\title{
Features of Forming an Interaction Network of an Entrepreneurial Structure
}

\author{
Anvar V. Gumerov ${ }^{1}$, Larisa E. Fatikhova ${ }^{2}$, Konstantin O. Kolpakov ${ }^{3}$, Karina R. Nabiullina ${ }^{4}$, Irina Y. Litvin ${ }^{5}$, \\ Svetlana Y. Suchkova ${ }^{6} \&$ Guzel F. Yusupova ${ }^{2}$ \\ ${ }^{1}$ Kazan National Research Technical University named after A. N. Tupolev, Kazan, Russia \\ ${ }^{2}$ Kazan (Volga region) Federal University, Kazan, Russia \\ ${ }^{3}$ Moscow State Institute of International Relations, Moscow, Russia \\ ${ }^{4}$ Kazan State University of Architecture and Engineering, Kazan, Russia \\ ${ }^{5}$ Moscow State University of Mechanical Engineering, Moscow, Russia \\ ${ }^{6}$ Gzhel State Art and Industry Institute, Ramensky region, Russia \\ Correspondence: Anvar V. Gumerov, Kazan National Research Technical University named after A. N. Tupolev, \\ K. Marks Street 10, Kazan, Tatarstan, 420111, Russia. E-mail: solo73@inbox.ru
}

Received: December 29, 2014

Accepted: January 22, 2015 Online Published: February 11, 2015

doi:10.5539/res.v7n4p209

URL: http://dx.doi.org/10.5539/res.v7n4p209

\begin{abstract}
The purpose of this article is aimed at identifying features of forming an interaction network of an entrepreneurial structure for developing real competition. The presented article defines the formation of different types of cross-cutting strategic management processes of an entrepreneurial structure with divergent interests of employers and hired managers. The basis of the presented work appears to be the use of modeling in the theory of relations between business structures. The paper presents a mechanism for forming an interaction network of an entrepreneurial structure with counterparties of direct exposure environment. This article is intended for managers, executives, researchers involved in entrepreneurial structures development.
\end{abstract}

Keywords: entrepreneurial structures, agency conflict, an interaction network, competition, modeling

\section{Introduction}

\subsection{Background}

In the basis of modern ideas about effective management of the interaction between market participants there is a complex of management approaches which have been dynamically developing abroad for several decades already, finding throughout the last decade the reflection in contemporary Russian science, as well. Addressing the issues of competitiveness is currently being defined, including management of the relationships between market participants.

Over the past 20 years there have been significant qualitative changes in business practices that determined the rapid development of the relations theory. Currently, companies, including Russian ones, in order to create competitive advantages are increasingly using strategies corresponding to this dynamic theory. Creation of well-functioning inter-firm networks by Russian companies, as a result of controlling the strategic management processes, contributes to form sustainable competitive advantages in the Russian and international markets. As the foreign companies' experience shows, the higher the efficiency of interaction is between the companies, the higher is their level of competitiveness.

In this regard, consideration of issues on building and managing relationships of a firm with the network members as a new strategy for managing the strategic management processes of Russian companies seems relevant.

\subsection{Status of the Problem}

The firm's ability to create and maintain a competitive advantage through the use of complex organizational mechanisms of controlling relationships with other market players management, can be seen as its core competence, because the external environmental appropriateness of the firm is achieved by adjustment of 
internal resources and a change in its own activities. Entrepreneurial structures to a certain extent can choose the environment, thus improving their position in the transaction (Hakansson \& Snehota, 1989). Network connections - is a unique social resource, inaccessible and little to be copied by other market entities (Teece, Pisano, \& Shuen, 2003; Katkalo, 2006). Immaterial economic resources (knowledge and skills, popularity and reputation), formed in external relations, give the entrepreneurial structures distinctive identity in the market and provide them with sustainable competitive advantages (Coleman, 2001; Radaev, 2003). Meanwhile, all researchers, regardless of affiliation to a particular scientific field, noted that network forms of organization are the basis for developing modern business, complementing the vertically-integrated companies (Rudenko \& Popova).

\subsection{Analysis of the Experience in Managing Interaction of Market Participants}

Depending on the research objectives, different approaches to classification of models are used. Within the framework of constructing models for managing the relationships portfolio, various ways to assess the market entities and the relationships with them are offered, for example, on the basis of: attractiveness of the partner and the degree of dependence on it (Olsen \& Ellarm, 1997); coherence of interests and values of relationships with partners (Kusch, 2008; Yuldasheva \& Gorodilov, 2009); the risk of doing business and the added value of the counterparty product (Wilson, 1995); the attractiveness of the partner and its strategic compatibility with the company (Gurkov, 2008) and others.

As a result of controlling the strategic management processes from the perspective of network business, researchers analyze the essential content of the "interaction" phenomenon, the possibility of counterparties' relationships, service with such objects as companies operating outside the network, and network business-structures, as well as whether the relationships are the result of interpersonal and impersonal relationships or just an intermediate factor in their establishment (Ford, 1998; Christopher et al., 2002). Besides, different forms and types of the existing relationships in business are investigated (including the so-called customer loyalty), and the development prospects of the entrepreneurial structure interaction network are assessed as a result of controlling the strategic management processes in the network business. Thus, the spread of network forms of business organization has led to a reconsideration of the main provisions in the traditional theory of strategic management and expansion of using tools for strategic managing the market networks, i.e. the strategy for managing relationships in market business networks. In such a way, within the network approach a market is interpreted as a network of interconnected agents and clearly structured phenomenon.

\section{Materials and Methods}

\subsection{The Concept of Forming an Interaction Network of an Entrepreneurial Structure}

As the basis of this research it is possible to offer the approach proposed by Meller and Halinen (2000) who distinguish four levels of entrepreneurial structures relationship management in the industrial market: a branch network; a central network; a portfolio of relationships; individual relationships with suppliers and customers.

The main idea of the concept of forming an interaction network of an entrepreneurial structure as a result of controlling the strategic management processes is that the object of management becomes the relationships with direct counterparties of an entrepreneurial structure. In contrast to the classical strategic management this type considers communications with counterparties in a broader context: as any long-term relationship between a company and its partners to facilitate extraction of profits and meet the needs of regular customers. Effective interaction with partners allows a company to stabilize the market space, to achieve greater demand controllability, and hence the higher stability of the business, which is increasingly being implemented not by a large corporation, but a whole network of interconnected partners.

\subsection{Modeling the Interaction Network of Entrepreneurial Structures}

Organization of rational interaction of the market network subjects is considered as a difficult task, the effectiveness of the solution of which depends on a number of factors. These include the nature and type of the organizational structure of the network, the complexity of its tasks, the network subjects' interaction regulations, procedures to manage their actions, which reflect the dynamics of interaction between the subjects.

All other conditions being equal, the entrepreneurs and hired managers in strategic management tend to form different types of networking with counterparties of direct exposure external environment. At the same time hired managers prefer to generate network connections only when the value of a potential counterparty eigenvector is higher than the industry average, which allows in minimizing the number of economic ties to ensure maximum agent availability of the generated interaction network, which is formalized as follows: 


$$
\mathrm{u}_{\text {esev }}(\mathrm{g}+\mathrm{ij}) \geq \mathrm{u}_{\mathrm{es}}(\mathrm{g})
$$

where $u_{\text {esev }}$-is a future integral utility of the generated entrepreneurial structure interaction network, complemented by a new relation, the formation utility criterion of which appears to be the economic agent's eigenvector, with which the possibility of forming the connection is considered;

$\mathrm{g}$ - is a matrix of the formed ties between economic agents of entrepreneurial structure interaction network;

$\mathrm{ij}$ - is communication, the possibility of forming which is considered by the entrepreneurial structure;

ues - is the current integral utility of the generated interaction network of the entrepreneurial structure.

When forming an interaction network in the framework of realizing strategic planning processes by a process owner-who is the principal, the relationships with counterparties of the direct exposure external environment are generated both at a high eigenvector, as well as when it is provided that the counterparty is in connection with the adjacent components representatives, and also at a high value of the counterparty's connectedness with other network agents, that can be formalized as follows:

$$
\mathrm{u}_{\mathrm{esc}}(\mathrm{g}+\mathrm{ij}) \geq \mathrm{u}_{\mathrm{es}}(\mathrm{g})
$$

where $\mathrm{u}_{\mathrm{esc}}$ - is a future integral utility of the generated entrepreneurial structure interaction network, complemented by a new connection, the formation utility criterion of which is the eigenvector of an economic agent, or the economic agent's relatedness with other elements of the network, with which the possibility of forming connections is considered.

\section{Results}

\subsection{Interaction Network Parameters of Entrepreneurial Structures}

Since the transition to modern methods of management is inextricably linked to network companies, network organizational structures, more and more organizations are recently realizing the benefits of developing strong relationships, which support the interaction of an entrepreneurial structure including the very company and other organizations (suppliers, bankers, distributors, major customers ), with which long-term reliable relationships are created. To the parameters of network interaction, primarily, can be attributed the organizational forms of cooperation between the companies. In a wide range of the existing organizational forms of firms' interaction at least three peer groups can be identified: interaction based on various forms of joint ownership of assets; interaction, built on contractual relationships, and informal cooperation agreements.

An important element of cooperation in business networks concept is such an indicator as marketing compatibility. Marketing compatibility can be characterized as the ability of the network subjects to operate in a specific marketing situation without compromising the defined (planned) parameters of marketing systems efficiency in each of the entities included in the network. At that, the marketing situation is seen as an environment created by a set of marketing events undertaken by business entities within their existing marketing potential. From an economic point of view, the deviation (decrease) of the marketing conditions level can lead to a decrease in the level of marketing compatibility, and in some cases - to a decrease in the efficiency of partners and the network interaction as a whole. In such situations, the consumers, the dealers, the suppliers and buyers can act as catalysts in the process of maintaining the business network entities' marketing compatibility. Thus, to act as a factor that ensures growth of values in each company, being a member of the network, and accordingly the network value growth, as a whole.

\subsection{Features of the Network Approach to Organize Interaction of Entrepreneurial Structures}

First, in this approach the relationships in the network are interpreted as a resource, and their presence-as a competitive advantage. The closer the relationship, the greater it is, since stable relations between the agents in the network create barriers for other firms to entry into this market, as well as provide exclusive access to its opportunities.

It follows from these features that the operating entrepreneurial organizations in the network prefer to invest in the relationship. Often, these investments are not as expensive as, say, in purchasing new equipment, but let the entrepreneurial structure reach a higher level of production. However, one should bear in mind that the more it is invested in the relationships with a partner, the greater are the potential costs of their breach.

The analysis of the conceptual and theoretical foundations of organizing the process of interaction in market networks allows formulating basic components of the interaction effectiveness: effect of long-term relations, interrelations of the network subjects; more efficient use of existing resources; improving the quality of network products customer value; reducing the risks of interaction through redistributing them between the network 
subjects; increase in the stability of information links; network participants' coherence improvement; the effect of introducing standard solutions into the network; increased confidence, image, the importance of network members' brands; flexibility improvement in the behavior of large entrepreneurial organizations.

\subsection{Plan of Organizing Interaction between Network Partners}

The presence of a large number of factors that influence the formation and development of interaction in the network, determines the need to develop a plan of organizing interaction between business-partners in the network, which may include a series of steps, which would contribute to the solution of the key tasks:

1) Analysis of the interaction state between the subjects in the network and justification of problematic relationships;

2) Preparation, analysis and ranking of interaction goals, taking into the account the management level;

3) Rationale for the method of cooperation in order to achieve the objectives;

4) Design of a possible plan for organizing the interaction between the network subjects;

5) Formation and analysis of a set of subjects and management levels for possible interactions (actions) between the subjects of the network;

6) Aggregation of the structural characteristics of the subjects in relation to the relationship level;

7) Distribution of relations between the subjects and levels of interaction. Analysis of options;

8) Justification of the required conditions for carrying out liaison with the view of possible restrictions;

9) The cause-consequence analysis of selected variants of distributing relations between the subjects and levels in the network management.

\subsection{Building an Interaction Network of Entrepreneurial Structures Based on Relationships with Counterparties}

A promising research area on the effectiveness of interaction between entrepreneurial structures is to analyze the control of strategic management processes by different types of the related entrepreneurial structure processes owners at different levels of relationships with counterparties and inter-firm network management (branch, central, portfolio of relationships; personal relationships with suppliers and customers). Each of these levels corresponds to a certain managerial ability, which a business structure should have in order to be able to successfully compete in the modern conditions of inter-firm networks development: the ability of "Network Vision", the ability to manage the core network, the ability to manage a portfolio of relationships and the ability to manage individual relationships. This approach makes it possible to comprehensively study the relationships and inter-firm networks in terms of managerial decisions.

When constructing the networking strategy it is also important to consider some aspects which may lead to risk of relationships breach. Ignoring the presence of a dominant business structure in the value chain and those "structural distortions" that it brings, is fraught with distortion of real coordination mechanism for entrepreneurial structures interacting in the network. Therefore, in an effort to more adequately reproduce the actually existing coordination mechanism in the value chain, the place and role of the dominant element should be determined.

With the growth of the strengthened ties share among counterparties in an entrepreneurial structure the probability of its survival increases, but when this share reaches a certain threshold, the probability begins to fall again. The identified dependence suggests that relying exclusively on a casual market, or, conversely, rooted connections, reduces the ability to survive, the best choice appears to be their reasonable combination.

Thus, the interaction can be viewed as total activity in the network, characterizing the degree, ways and forms of mutual influence of network subjects in the process of achieving or stated objectives and mutual satisfaction of the current needs.

The formed on the basis of the presented approach circuit of generating an interaction network was constructed with Pajek software for 25 interaction network agents of the direct exposure external environment and is shown in Figure 1. 


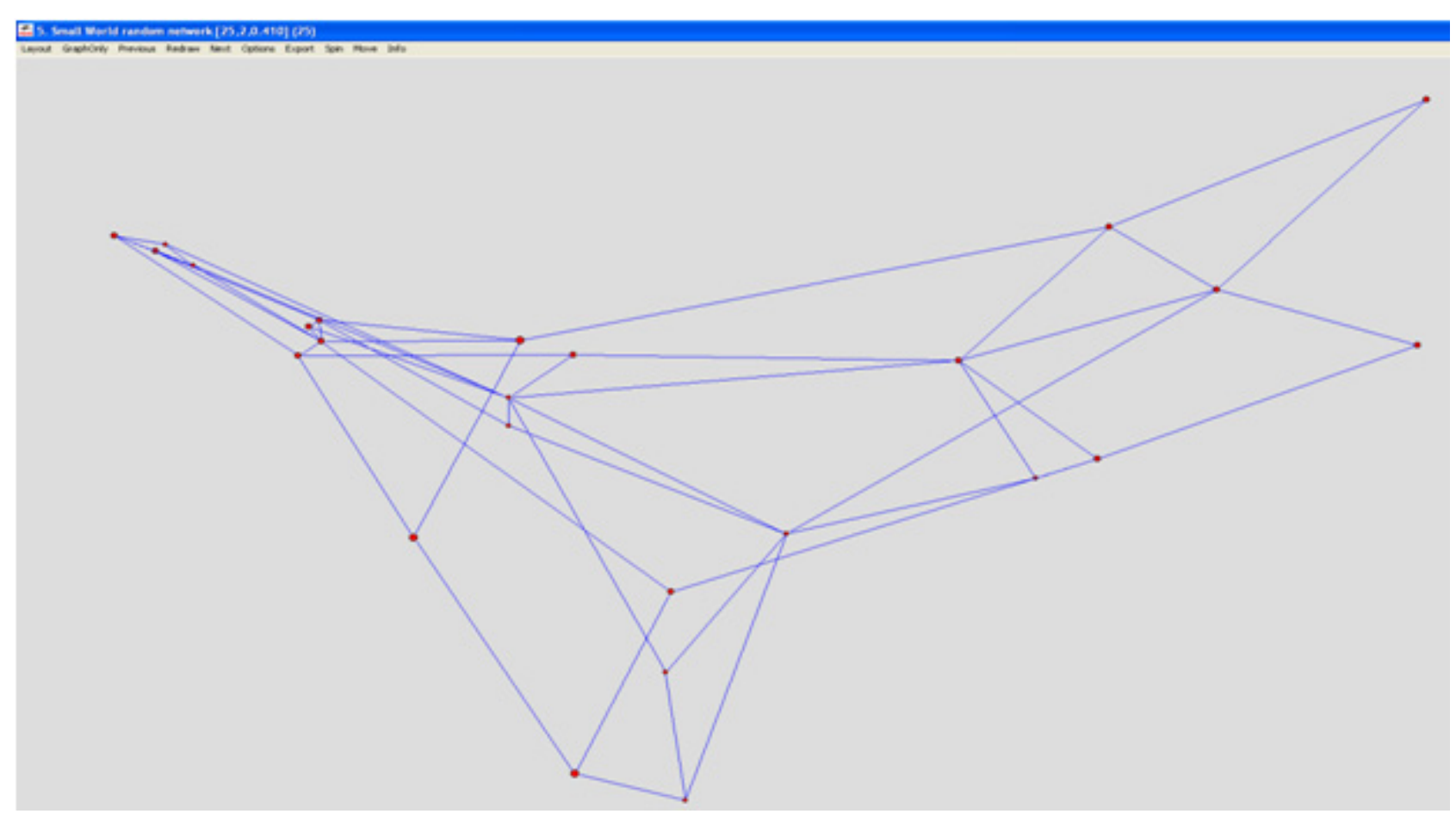

Figure 1. An interaction network of an entrepreneurial structure with counterparties of direct exposure environment (the situation: Agent)

The modeled in Pajek resulting interaction network, the size of which is similar to the size shown in network Figure 1, is shown in Figure 2. 


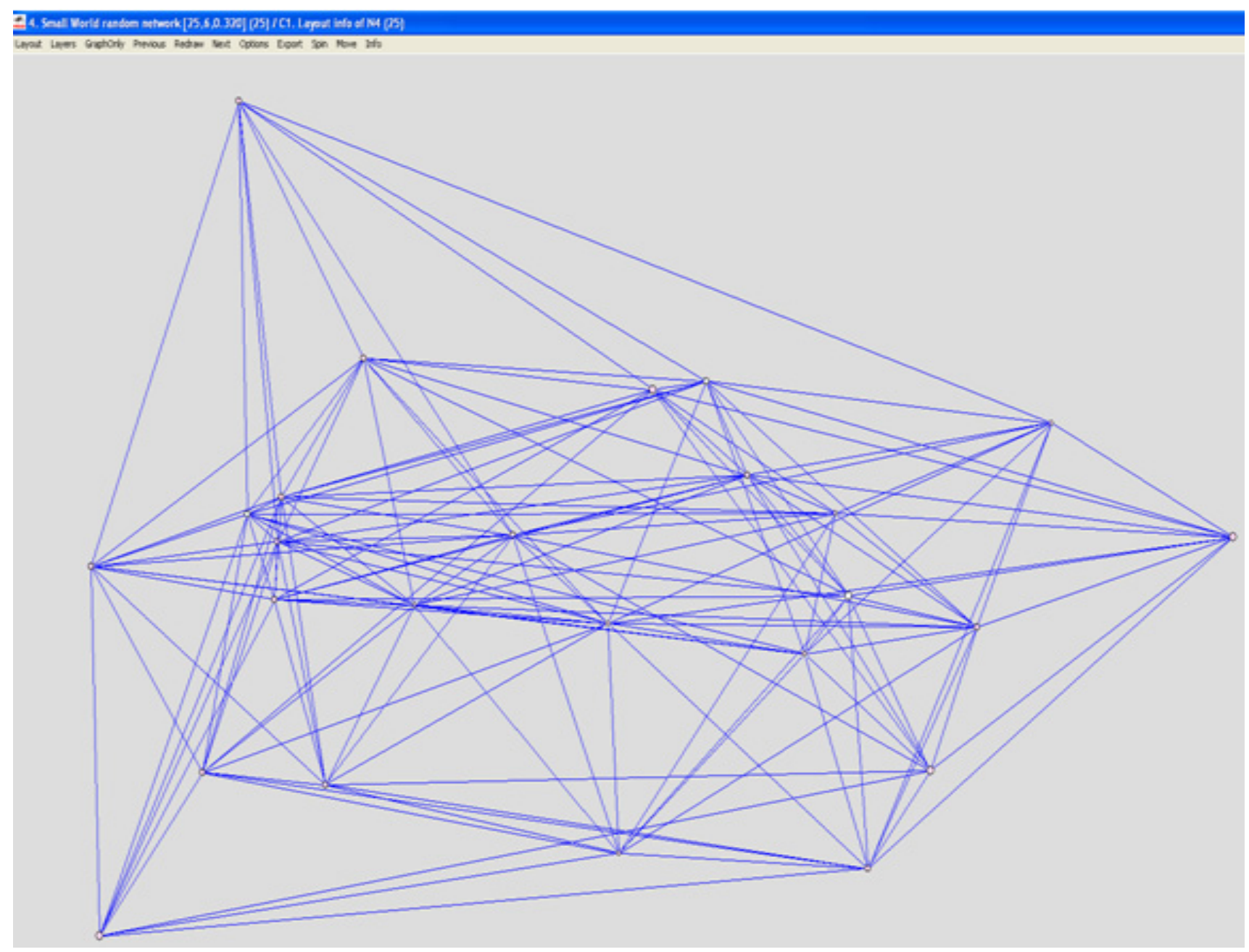

Figure 2. An interaction network of an entrepreneurial structure with counterparties of direct exposure environment (the situation: Principal)

As it is seen from figure 2, the network cohesion when it is formed by the principal is substantially above, that has dual effects. On the one hand, the cost of maintaining relationships in an extensive network is higher, which results in efficiency decline when used by an entrepreneurial structure in a short term; on the other hand, in a strategic perspective the use of an extensive network results in substantially reduced development transaction costs.

\section{Discussions}

The members of the interaction process - are different market actors. In the case of interaction within the network, the participants in this process are producers of business services, on the one hand, and business services buyers, on the other hand. In practice, every single business structure in the market in the normal course of business contacts with many different actors (producers, competitors, intermediaries, consumers, government agencies). In this case, the concept of interaction goes beyond "producer-consumer" relations. The most important characteristic of entrepreneurial structure in this case becomes the ability to effectively interact with network partners. From this follow the following distinguishing features of the proposed concept: an entrepreneurial structure is not considered in isolation, it is closely linked with the surrounding agents and considers its work in organic conjunction with the actions of its agents and counterparties across the network. When using the network approach, an entrepreneurial structure with market launch of a new product is looking for a promising network; integrating into the latter, it is subject to constant repositioning based on the specifics of networking in general.

\section{Conclusions}

Thus, it is proved, that in designing an interaction network of an entrepreneurial structure as a result of 
controlling strategic management processes by different types of owners of the relevant processes (the principal and the agent) different types of network interactions are formed with direct counterparties of the entrepreneurial structure, based on randomization of the formed relationships amount based on various priority of their construction, at which wage management is committed to building relationships with counterparties that have a high index of links on eigenvector criterion, whereas the entrepreneur generates connections also with counterparties having high connectivity, primarily with neighboring components of the network, i.e. entrepreneurs in the network formation process are oriented first of all to a long term perspective, and hired managers - to a short term.

\section{Acknowledgments}

The authors thank all participants of this study for their kind cooperation.

\section{References}

Christopher, M., Payn, A., \& Ballantyne, D. (2002). Relationship Marketing (p. 242). Creating Stakeholder Value.Oxford, UK : Butterworth-Heinemann.

Coleman, G. (2001). Social and human capital. Journal of Social sciences and the present, 3, 121-139.

Ford, D. (1998). Managing Business Relationships (p. 292). N.Y.: Publishing house "John Wiley \& Sons”.

Gurkov, I. B. (2008). Strategy and structure of corporations (p. 288). Moscow publishing house "Business".

Hakansson, H., \& Snehota, I. (1989). No Business is an island: The network concept of business strategy. In D. Ford (Ed.), Understanding Business Markets (pp. 136-151). London the Dryden Press.

Katkalo, V. S. (2006). The evolution of strategic management theory (p. 548). Saint Petersburg University Press.

Kusch, S. P. (2008). Marketing relationships in industrial markets (p. 272). SPb.: High School of Management Press.

Meller, K. M., \& Hallinen, K. A. (2000). Relationships Marketing Theory: Its Roots and Direction. Journal of Marketing Management, 16, 29-54. http://dx.doi.org/10.1362/026725700785100460

Olsen, R. F., \& Ellram, R. L. (1997). A portfolio approaches to supplier relationships. Journal of Industrial marketing management, 26, 101-113. http://dx.doi.org/10.1016/S0019-8501(96)00089-2

Popova, Y. F. (2008). Inter-firm networks in industrial markets in Russia: Theory and practice management (monograph) (p. 355). SPb Science Publishers.

Radaev, V. V. (2003). Understanding of capital, forms of capital and their convertibility. Journal of Social sciences and the present, 2, 5-16.

Rudenko, M. (2010). Marketing communication and network theory. Journal of Marketing, 6, 41-48.

Teece, D. J., Pisano, G., \& Shuen, A. (2003). Dynamic Capabilities and Strategic Management. Journal of Herald Saint-Petersburg university, 4, 133-183.

Wilson, D. T. (1995). An integrated model of buyer-seller relationships. Journal of Academy of Marketing Science, 23(4), 335-345. http://dx.doi.org/10.1177/009207039502300414

Yuldasheva, O. U., \& Gorodilov, V. A. (2009). Strategies for interacting with customers and estimation of their efficacy (pp. 112-124). Proceeding from international scientific conference "The interaction marketing in innovation economy". SPSUEF.

\section{Copyrights}

Copyright for this article is retained by the author(s), with first publication rights granted to the journal. This is an open-access article distributed under the terms and conditions of the Creative Commons Attribution license (http://creativecommons.org/licenses/by/3.0/). 